\title{
Malignant osteopetrosis: hypercalcaemia after bone marrow transplantation
}

\author{
P S M Rawlinson, R H A Green, A M Coggins, I T Boyle, B E S Gibson
}

\begin{abstract}
A 3 year old girl presented with malignant osteopetrosis, which was treated by allogeneic bone marrow transplantation. Successful engraftment was complicated by prolonged hypercalcaemia, which was controlled by a combination of a bisphosphonate, phosphate infusions, vigorous resalination, and salmon calcitonin. She was alive and well 16 months after the transplant.
\end{abstract}

\section{Case report}

A female infant was born vaginally at term after an uneventful pregnancy to healthy unrelated parents. Development was normal until a squint was noted at 7 months. Subsequent radiological examinations showed that she had osteosclerotic bones. A bone marrow biopsy specimen showed osteopetrosis. At 36 months she received an allogeneic bone marrow transplant after preparation with cyclophosphamide and single fraction total body irradiation.

By day 34 her sustained neutrophil count was over $1.0 \times 10^{9} / 1$, and the adjusted serum calcium concentration was $2.56 \mathrm{mmol} / \mathrm{l}$. This increased within 48 hours to $3.67 \mathrm{mmol} / \mathrm{l}$ (fig 1). Initial treatment consisted of methylprednisolone (40 $\mathrm{mg} / \mathrm{kg} /$ day) and a forced diuresis of normal saline $3 \mathrm{l} / \mathrm{m}^{2} /$ day with boluses of frusemide (1 $\mathrm{mg} / \mathrm{kg}$ ). The hypercalcaemia persisted over the next two days and salmon calcitonin $60 \mathrm{IU} /$ day was added to the regimen. Later the same day her level of consciousness decreased and she required assisted ventilation. The adjusted serum calcium concentration at this time was

Royal Infirmary, Glasgow G4 OSF Department of Haematology P S M Rawlinson

University Department of Medicine I T Boyle

Department of Haematology, Royal Hospital for Sick Children, Glasgow

R H A Green A M Coggins B E S Gibson Correspondence to: Dr Rawlinson.

Accepted 12 December 1990 (ArchDisChild 1991;66:638-9)

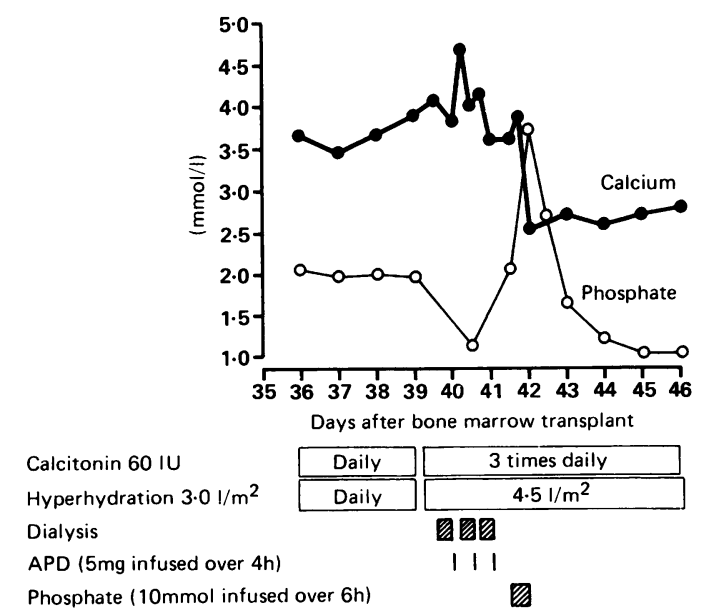

Figure 1 Response of serumcalcium and phosphate concentrations to the treatment given during the first hypercalcaemic crisis.
4.07 $\mathrm{mmol} / \mathrm{l}$ and her carbon dioxide tension was $13.8 \mathrm{kPa}$. The forced diuresis was increased to $4.51 / \mathrm{m}^{2} /$ day with frusemide $1 \mathrm{mg} / \mathrm{kg} / \mathrm{hr}$ as a continuous infusion, and the salmon calcitonin was increased to 60 IU three times a day. She was dialysed against a low calcium dialysate (Renalyte S519, Macarthy's Laboratories, Romford) for three six hour periods during the next 48 hours. After each dialysis she was given $5 \mathrm{mg}$ of aminohydroxypropylidene bisphosphonate (APD) intravenously. Despite these measures the serum calcium concentration remained above $3.67 \mathrm{mmol} / \mathrm{l}$ and she had prolonged episodes of bradycardia. Phosphate $10 \mathrm{mmol}$ was given as an infusion over six hours, which reduced the serum calcium concentration to $2.54 \mathrm{mmol} / \mathrm{l}$. The serum phosphate concentration increased from 2.06 to $3.70 \mathrm{mmol} / \mathrm{l}$ and returned to normal 24 hours after completion of the infusion. She was extubated three days later.

She had four further hypercalcaemic crises despite continuing treatment with salmon calcitonin 60 IU three times a day (fig 2). The last occurred 148 days after transplantation. Each was successfully controlled with a forced diuresis of $3 \mathrm{l} / \mathrm{m}^{2}$ normal saline, a single dose of APD $5 \mathrm{mg}$, and an infusion of phosphate $5-10 \mathrm{mmol}$ if the calcium concentration rose above 3.0 $\mathrm{mmol} / \mathrm{l}$.

At discharge, 178 days after the transplant, the adjusted serum calcium concentration was stable $(2 \cdot 6-2.9 \mathrm{mmol} / \mathrm{l})$. A maintenance dose of salmon calcitonin 60 IU three times a day on alternate days was continued, and was reduced over the next four months.

Sixteen months after the transplant the hepatosplenomegaly had resolved, her neurological

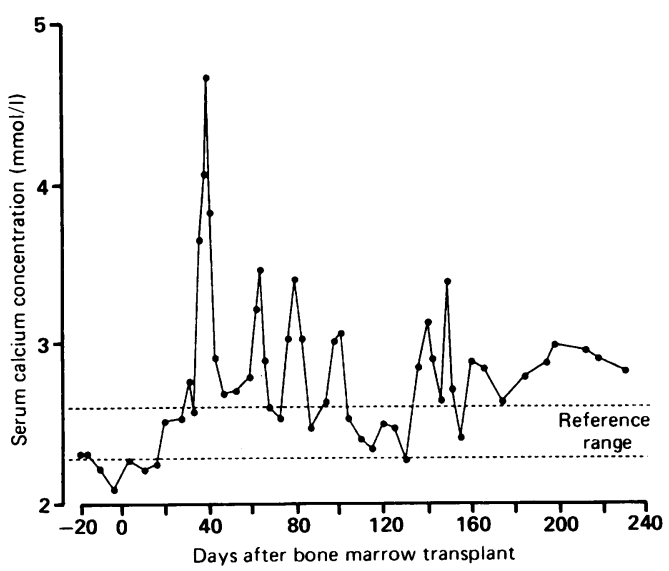

Figure 2 Serumcalcium concentrations from 20 days before to 240 days after bone marrow transplantation (reference range $2 \cdot 27-2 \cdot 59 \mathrm{mmol} / \mathrm{l}$ ). 
abnormalities were no worse, and her osteosclerosis had improved both histologically and radiologically. The graft was intact and of donor origin. She was well, intellectually bright, and attending a preschool for the blind.

\section{Discussion}

In this case engraftment was followed by a rapid rise in the calcium concentration, and hypercalcaemia recurred on a number of occasions. A management plan to control the serum calcium concentration during these acute phases and to maintain long term normocalcaemia evolved with experience. In the acute phase the hypercalcaemia seemed to be controlled primarily by a combination of rehydration, intravenous phosphate infusions, and a bisphosphonate. Calcitonin was useful as a maintenance agent but was not completely effective alone.

Phosphate infusions produced a rapid, dose dependent reduction in the serum calcium concentration, which is directly related to the rise in the serum phosphate concentration. ${ }^{1}$ The serum phosphate concentrations returned to their pretreatment values within 24 to 36 hours of the infusion. The risk of soft tissue calcification after a phosphate infusion is therefore likely to be short lived. In our patient there was no radiological evidence of soft tissue calcification or of nephrocalcinosis, despite repeated phosphate infusions.

APD is thought to be localised and concentrated in hydroxyapatite, making bone more resistant to osteoclastic activity ${ }^{2}$; to inhibit osteoclast formation from stem cells at low concentration ${ }^{2}$; and to have a direct antiosteoclast effect at high concentrations. ${ }^{3}$ It should therefore be an effective drug in the management of hypercalcaemia after bone marrow transplantation for osteopetrosis as it would control osteoclast recruitment and activity. APD has not, to our knowledge, previously been used for this condition. The number of infusions required to regain control of the serum calcium became less with time, presumably reflecting the progressive reduction in total skeletal calcium load. Its long term use might, however, be associated with defects in mineralisation. ${ }^{4}$ For this reason salmon calcitonin, given by subcutaneous injection, was used as maintenance treatment. There was an incomplete (but nevertheless clinically useful) response to calcitonin, and at one year after bone marrow transplant the need to suppress accelerated bone remodelling disappeared.

\section{CONCLUSION}

Successful engraftment of older children with osteopetrosis is often complicated by severe hypercalcaemia. Acute episodes of hypercalcaemia can be controlled by resalination together with APD given intravenously and a phosphate infusion. The latter, although rapid may introduce a risk of soft tissue calcification and nephrocalcinosis. Salmon calcitonin was useful for maintenance treatment.

We thank Dr SH Ralston for his help and advice.

1 Fulmer DH, Dimich AB, Rothschild EO, Laird Myers WP. Treatment of hypercalcaemia. Comparison of intravenously
administered phosphate, sulfate, and hydrocortisone. Arch administered phosphate, sul

2 Boonekamp PM, van de Wee Pals LJA, van Wijk-van Lennep MLL, Thesing CW, Bijvoet OLM. Two modes of action of bisphosphonates on osteoclastic resorption of mineralised matrix. Bone and Mineral 1986;1:27-39.

3 Boonekamp PM, Lowik CWGM, van de Wee Pals LJA, van Wijk-van Lennep MLL, Bijvoet OLM. Enhancement of the inhibitory action on the transformation of osteoclast precursors into resorbing cells after demethylation of the amino group. Bone and Mineral 1987;2:39-42.

4 Cantrill JA, Anderson DC. Treatment of Paget's disease of the bone. Clin Endocrinol 1990;32:507-18.
Intensive Therapy Unit, Royal Hospital for Sick Children, Yorkhill, Glasgow G3 8SJ D R FitzPatrick C H Skeoch

Duncan Guthrie Institute of

Medical Genetics, Glasgow

J L Tolmie

Correspondence to:

Dr Skeoch.

Accepted 7 January 1991

(Arch DisChild 1991;66:639-41)

\title{
Genetic aspects of admissions to a paediatric intensive care unit
}

\author{
D R FitzPatrick, C H Skeoch, J L Tolmie
}

\begin{abstract}
Of 821 consecutive admissions to a paediatric intensive care unit, $47(5.7 \%)$ were for chromosomal or monogenic disorders. These patients had more readmissions, longer mean stays, and a higher mortality rate than the group as a whole. In two of the four cases that died of single gene disorders, failure to store DNA made genetic counselling difficult.
\end{abstract}

In developed countries genetic disorders account for about $6 \%$ of the admissions to general paediatric wards. ${ }^{1}$ New molecular genetic, cytogenic, and obstetric techniques offer families the prospect of avoiding recurrences of an increasing number of serious inherited conditions.

The aims of this study were to find out what proportion of the admissions to the paediatric intensive care unit were for the treatment of genetic diseases, and to audit the storage of DNA or tissues that are important for the subsquent counselling of families.

\section{Patients and methods}

The intensive care unit at this hospital is a 12 bedded unit and serves the west of Scotland, a population of roughly three million people. It 